\title{
Flashbacks and Flashforwards: Epidemics and Social Change (intro)
}

https://doi.org/10.51897/interalia/PYYJ9700

\author{
Rafat Majka \\ Andrzej Frycz Modrzewski Krakow University \\ ORCID: 0000-0001-5283-7572 \\ Justyna Struzik \\ Jagiellonian University \\ ORCID: 0000-0003-3381-6180
}

The idea of this special issue emerged in the context of the SARS-CoV-2 pandemic, which became a social and medical fact at the beginning of 2020. Although epidemics and pandemics differ profoundly - not only in terms of the strictly epidemiological or medical dimension of the disease outbreak but also with regards to social and political responses - they produce similar effects by intersecting with existing inequities, thus affecting various vulnerable populations and communities. In consequence, the disruptions they cause mobilise groups and individuals to seek recognition of their rights, fight for equal access to healthcare and stand up against discrimination and social exclusion. The last point became for us a point of departure to think about and conceptualize this special issue.

Andrew T. Price-Smith claims that "contagion also contains the seeds of catalytic socio-economic and political transformation" (2009: 2); and in their introduction to the book The Anthropology of Epidemics, Ann H. Kelly, Frédéric Keck and Christos Lynteris argue that "the inevitable and yet unpredictable emergence of new epidemics and pandemics" (2019: 2) provokes us to pose a question about possible futures for humanity. Epidemics and pandemics that have roamed humankind so far have been turning points in many different ways. For example, the Black Death is thought to have paved the way for capitalism, while the Western manifestation of the HIV/AIDS epidemic decimated a whole generation of queer people, tainting the gay identity experience. The COVID-19 pandemic has already shown the drawbacks of slimmed-down, underfinanced and understaffed, or privatised institutions of social care. Yet, by redefining the moral economy of life and death, each of these outbreaks of diseases changed the dominant ways of thinking about social relations and provoked individuals and collectivities to invent new forms of solidarities and care.

Epidemics work in contradictory ways, on the one hand - causing established social patterns to fade away, on the other - inspiring people to forge strong connections of solidarity and communal care. It is in the times when new or recurring pathogens appear that the social lines of privilege and abandonment, or stigma and discrimination, are most vividly laid bare. Those who are deemed worthy by 
the system or who actually are worthy, economically speaking, receive as much care and as little supervision as the conditions allow, whereas social groups that do not sit comfortably with the normative narratives of the nation-state (be it migrants, gays, sex workers, trans* people, people who use drugs, or working-class people in general), are cordoned off, violently monitored, or left out of the system.

If we look at the recent events taking place in Poland and beyond, we observe a certain shift towards the introduction of penal measures in governing the pandemic. In Poland, this move towards criminalisation bound the HIV and coronavirus epidemics together. In March 2020, the Polish government introduced the so-called "anti-crisis shield" to manage some of the economic and social consequences of the pandemic. In cases where someone, "knowing that they are infected with HIV, directly exposes another person to such infection," the government increased penalties from three years to up to eight years of imprisonment. This change was introduced with no justification or public debate. At the same time, the regulations were modified to include coronavirus transmission in the penal code. However, real regulatory practice regarding the coronavirus epidemic runs counter to the force of the written legal provisions. With the spread of new variants of SARS-CoV-2 and the sharp rise in infection rates, the government chaotically maneuvers among makeshift restrictions, treading carefully among its present and prospective constituencies. Anti-mask and anti-vaccine advocates roam the public space undisturbed while people who live with HIV and who are on TasP are traumatized into social and sexual hiding with the said Art. $161 \S 1$ of the Polish Penal Code regarding the exposure of another person to HIV infection. Even if, in the light of present-day medical knowledge, their HIV status is undetectable so they cannot "directly expose another person to HIV infection," they bear the brunt of this symbolic muscling up of the right-wing state. They appear easy victims, with all the ideological burden of the HIV/AIDS epidemic.

The COVID-19 pandemic has again brought to the front the realization that it is socially and economically vulnerable groups who are most affected during an epidemic, and that the demonization or monsterization (Dziuban et al., 2021) of particular communities in a folk way identified as the agents or "carriers" of the virus/disease (for HIV/AIDS - gay men, sex workers or people who use drugs, and for COVID-19 - people who "look Asian," paramedics or animals), runs along a violent, survivalist logic unhinged from scientific or medical findings. In his "Queer Epidemics" contribution to this issue, Tomasz Sikora elaborates on the logics of social exclusion and immunization, cultural dynamics of epidemics, and fear of contagion.

In the coronavirus pandemic, working-class bodies have been disproportionately affected in comparison with (upper) middle-class ones. During lockdowns, or with harsh restrictions regarding public and working spaces, workers who do manual work or provide services which need direct interaction between people, still had to leave their homes and risk exposure to the coronavirus. White-collar workers could and, to a large extent, still can work from home. In some countries class divisions overlapped with the dynamics of (the remnants of) structural racism, for instance in the US non-white 
Americans were hospitalized much more often than their (upper) middle-class white compatriots because of socioeconomic status which translates into access to health care, household nutrition and lifestyle habits, thus health conditions ${ }^{1}$.

In this special issue, we are interested in how epidemics intersect with social inequalities, how they affect different populations, and also to what extent and in what ways they shape the cultural imaginaries of such categories as health, life, death, and rights and political subjectivities. Of course, we tend to think about all these global questions through a local lens in which our experiences and observations are embedded. Our local Polish context seems to be significant, too. Following other scholars and activists in rediscovering non-hegemonic stories of HIV/AIDS epidemics (e.g. Rosengarten et al., 2021; Chantraine, Molle and Musso, 2019), we sought contributions that would question or problematize the dominant narrative(s) about HIV epidemics, activism and policies in the local context. However, the current pandemic has thwarted our plans to some extent. Academia and activism, often characterized by precarity, have become even more unstable and unpredictable in the coronavirus era, making the everyday work of many of us more difficult. In consequence, not all of the commissioned articles were ultimately submitted.

While thinking about this special issue, we kept asking ourselves about the local histories of epidemics. Of particular interest to us were HIV/AIDS policies and activism that have emerged in Poland. We were also considering to what extent social imaginaries of HIV have been shaped by the temporal coincidence of the epidemic developments and policy responses with the post-1989 political and economic transition from state socialism to capitalism. We were looking at the stories told by activists about transnational cooperation in the 1990s, exploring the very first measures introduced to respond to the virus, and reflecting upon various social figures produced in the HIV/AIDS context by medicalised and community discourses. This period has been described in literature through the notion of "thick" times which "is meant to reflect a certain congestion of actors, events, emotions, actions and ideas, which are in progress and remain fluid" (Struzik, 2021: 571). The "thickness" of the 1990s manifested itself, for example, in an extensive transfer of knowledge and practices taking place between (mostly Western) non-governmental organisations (such as AIDES in France ${ }^{2}$, Noah's Ark in Sweden or Deutsche Aidshilfe in Germany) during workshops, study visits and conferences. This wave of transnational collaboration not only brought certain vocabularies and categories to grasp complexities and contradictions of the epidemic, but it also allowed activists and policy-makers to bond and transgress institutional boundaries. One of the policy-makers active in the 1990s recalls this moment in the following way:

\footnotetext{
${ }^{1}$ Though inner cities and reservations, which are inhabited mostly by non-white working-class Americans, lack proper medical care infrastructure.

2 See the interview with Bruno Spire in this issue.
} 
And actually, at this moment, I think, this boundary between civil society representtatives and us - so-called bureaucrats - vanished. We had a lot of meetings, actions together, we were learning together, and together we participated in workshops ${ }^{3}$.

Activism rooted in friendship and care in the context of epidemiological crisis is also explored in Robert Kulpa and Katherine Ludwin's article "The Potential of Friendship: A Case for Social Resilience." The authors show how shifting our focus in thinking about sociality to friendship might help us to escape heteronormative social orders constantly reproducing the (nuclear) family as a crucial building block of the society. Despite this perpetual reproduction, marginalized communities and groups create friendships and nonheteronormative intimate relations which make them more resilient in the realm of the pandemic. The meaning of community care during the early HIV epidemics is also discussed in the article "A Litany of Saints: Remembering the Early Years of AIDS Coalitional Activism in the First Year of a New Pandemic" by Mary Foltz, Adrian Shanker, Liz Bradbury, and Kristen Leipert. The stories of the HIV/AIDS activists quoted in the article expand commonplace definitions and practices of care by embracing not only concerns for health and well-being, but also housing, social and emotional needs. Solidarity was also at the heart of the formation of the French organization AIDES, as Bruno Spire recalls, pointing to the role of self-help groups, volunteers, and patients themselves in shaping the response to the HIV epidemic. All those aforementioned affects and feelings certainly constituted an important social context for many artistic works which were produced in response to the HIV/AIDS epidemic. In "All the Rage: A Partial Memoir in Two Acts and a Prologue" Nils Clausson reviews the memoir of famous Canadian playwright Brad Fraser who has written, in quite a touching way, on loss, despair but also solidarity and affection in relation to the HIV/AIDS epidemic. Taking the affects and practices of solidarity and care beyond anthropocentrism, Laura Murray in her article "In the Margins of One Health: Interspecies Solidarity, Care, and Inequality" shows vernacular challenges to normative Western assumptions regarding the contexts of (re)emerging zoonotic diseases, painting in her ethnographic narrative pictures of interspecies bonding and care.

While community responses remain essential to understanding social inequalities but also to changing them, epidemics provoke punitive actions against vulnerable populations. Drawing on our fieldwork, we may observe how the HIV/AIDS epidemic intersected with criminalisation of drug use and moralised public debates about nonheteronormative sexualities.

Poland, being a low prevalence country with a relatively stable epidemiological situation, fits the epidemiological picture of Central and Eastern Europe. One of the figures produced with HIV/AIDS policy worlds in the 1990s is the "drug user" (in Polish - "narkoman"). For years people who inject drugs were the population most exposed to HIV infections. With the dominant abstinence-based

\footnotetext{
3 The interview was conducted by Justyna Struzik as part of the Disentangling European HIV/AIDS Policies. Activism, Citizenship and Health (EUROPACH) project, financially supported by the HERA Joint Research Programme 3 Uses of the Past.
} 
treatment model and criminalisation of drug possession, gradually progressing since 1997, a person who uses drugs became inextricably associated in social imaginaries with criminality (see Struzik, "Narcophobia Meets Queerphobia" in this issue). As Kasia Malinowska (2017: 158) puts it, "drug use, previously considered a social and medical issue, was re-framed as a problem of law and order in which drug users were viewed as criminals, social outcasts, threats to public safety, associates of the Russian Mafia and perpetrators ready to attack law-abiding citizens with HIV infected needles."

Furthermore, the involvement of the Catholic Church in shaping HIV prevention (Owczarzak, 2010) reinforced a moralized approach towards the virus and drug use, and reconfigured understanding and practising citizenship in regard to health:

As politics in Poland shifted to the right and aligned more closely with the church, the discussion over who does and does not deserve state-funded care became more dominant, as did the rhetoric of blaming the individual for their health outcomes. Having Polish citizenship was no longer sufficient qualification for statefunded public health measures or access to healthcare; in the new paradigm, one had to be morally deserving as well. (Malinowska, 2017: 158)

Throughout the last four decades the picture of HIV, both in terms of epidemiology and political discourses, has changed radically. Today gay men and other men who have sex with men are the key population in Poland with a visible increase in new HIV diagnoses. As in the case of drug use being criminalised and stigmatised, nonheteronormative sexualities face growing homophobia and transphobia (for example, so-called LGBT-free zones established by local authorities, smear campaigns run by some right-wing politicians, denigration of queer and feminist collectives and NGOs, banning of sex education in schools, and trans-exclusionary voices among activists). Yet, these experiences and processes should be placed in a broader framework and explored through ways in which sexualities and sexual practices are governed and managed.

Queerphobic discourses, legal regulations and everyday practices taking place in education, medical and political settings, point to disciplining, controlling and silencing as the dominant tools of governing. This can be observed, for example, in the context of pre-exposure prophylaxis (PrEP). While PrEP is one of the most effective HIV prevention methods and a number of countries have started to reimburse it, it remains to some extent "unrecognized" and "silenced" by public institutions responsible for HIV prevention in Poland. PrEP has been pushed into the private healthcare sector, accessible for some (usually wealthier) persons. When PrEP was introduced in the Western context, discussions emerging around this form of chemoprophylaxis, usually in social media and (sex) dating apps, tended to present highly moralised vision of sexuality, in which being on PrEP was framed as having "reckless," "irresponsible" sex, as if this was supposed to be linked with a certain punishment or at least a serious consequence. The conservative moral panic (especially among nonheterosexual communities), which produces such statements as: "Promoting medicine which persuades people to 
stop using condoms is sick, ${ }^{\prime 4}$ should be interpreted in the context of the long dominant discourse of HIV/AIDS prevention, that is, condom prophylaxis. For many gay men, and especially for a number of HIV/AIDS activists, condom safer sex has become, as Kane Race notices, "a habitual and ongoing practice" (2018: 104), a socialized pattern of sexual behaviour. Thus, "PrEP forces us to contend with what scares us, not only about risk but also about sex: how the condom has operated in the citizenship area, for example, not only as a piece of latex but also a symbolic prophylaxis against the apparently terrifying prospect of unbridled homosexuality" (ibidem, 101-102). And that "terrifying prospect of unbridled homosexuality" is what the post-HIV/AIDS epidemic gay activism was for many decades trying to keep as far at a distance as possible when activists managed to build a respectable, "virtually normal" image of a gay man in society and struggled to remove the HIV/AIDS stigma from gay identity. Condoms are not being discarded in HIV/AIDS prevention activism that focuses on GBMSM $^{5}$ communities, but it has been acknowledged that there are men who do not use condoms, who do not like using condoms, or who fail to use condoms (for example, during chemsex parties). Given the availability of other effective HIV/AIDS prevention methods, Bruno Spire claims in this issue, activist and community-based organizations should think of themselves as "trade unions of people," representing also those "who have problems with condoms" instead of fighting them.

Nowadays, the rhetoric of (the lack of) responsibility in the context of PrEP is used in various state and sociocultural discourses in different ways. In spaces where PrEP can be accessed free of charge, where sexual health testing and counselling infrastructure is co-financed or reimbursed by the state, and where public institutions embrace and support PrEP and $U=U$ activism, "being responsible" has drifted towards "being on PrEP" and/or "being undetectable." In 2017, the American Centers for Disease Control and Prevention officially confirmed the 2008 Swiss Statement regarding the health prevention effectiveness of antiretroviral therapy (ART), which is known as Treatment as Prevention (TasP), stating that when one becomes undetectable, there is no possibility and no risk of HIV transmission. Tim Dean notes that "the category of 'undetectable' disrupts the positive/negative binary (Lee, 2013). The drugs perform a kind of deconstruction on the binary opposition that has organized gay erotic life for decades" (2015: 241), moving us into, as Dean puts it with a kind of amusement, a "pharmaceutically mediated utopia," where the virus seems no longer to weigh heavily on sexual intercourse dynamics, because "'undetectable' poz guyz cannot pass on the virus and neg guys on PrEP cannot get it" (ibidem). This, however, is only the case in some developed Western economies that deliver TasP free of charge, co-finance or reimburse PrEP and PEP, and provide accessible sexual health infrastructure. Outside as well as inside "the West," there are many different spatial and temporal realities. On the one hand, this "pharmaceutically mediated utopia" seems to have brought the long-awaited end of HIV transmissions and AIDS deaths, at least in some Western states, yet, on the other hand, this utopia is a form of biopolitical government, as "it relies on surveillance at the biomolecular level by an entire apparatus of medical power" (ibidem) and, because it is provided by the state, it is contingent upon the ideological whims of the political state and pharmaco-capitalism. PrEP

\footnotetext{
${ }^{4}$ A PrEP-skeptical comment on a LGBT Facebook group. Trans. by RM.

${ }^{5}$ Gays, bisexual men and other men who have sex with men.
} 
and TasP have certainly been bridging the social and sexual worlds of HIV-positive and HIV-negative persons separated in the past by conservative ideologies and HIV-phobic discourses. For example, in gay communities one can find such accounts:

... it kind of made me feel good I don't have to ask guys what their status is and so poz guys don't have to worry about disclosure or rejection and you know all that stigma stuff, and I like the idea that they have a different experience now that there are so many guys on PrEP because some guys would just - like I don't ask. (Focus Group; Grace et al., 2018: 27)

However, with the growing awareness and accessibility of PrEP, (sex) dating apps for gays, bisexuals and other men who have sex with men have seen the emergence of users who, despite being undetectable on TasP, will identify themselves as "on PrEP." Both PrEP and TasP use similar combinations of drugs, and this "confusion" might be a deliberate move, that is, a strategic, sexual identity shielding from the HIV stigma (e.g. where sex between serodiscordant partners might get legally risky for the HIV-positive person); or it might also be the result of a lack of knowledge about the difference between these two biomedical technologies. Zoran Milosavljević writes about the (mis)use and social dynamics of PrEP in his article "The Paradoxes of PrEP: Rejection, Reluctancy, and Novel Gay Identities in Biomedical HIV Prevention in Serbia."

In 2018, the Polish right-wing government, trying to find money to fund its populist policies, sought to radically reorganize the ART financing policy. The aim was to lower the costs of ART per person, and one of the solutions considered by the Ministry of Health was to take ART out of the central state tender system and put it into the healthcare reimbursement system. This would mean, among other things, that people living with HIV/AIDS (PLWHA) would have to get their medicine from local pharmacies instead of their HIV outpatient hospital clinics. This change would likely exacerbate HIV/AIDS stigma-related fear and anxiety in a country whose state-run National AIDS Centre, in a video spot released in December 2021, debunks myths about HIV/AIDS in an anonymous silhouette interview with an HIV-positive woman and man, using voice pitch-shifting technology. In the end, ART was not introduced into the reimbursement system, yet the amount of money to be spent per patient was lowered. As a result, some combination antiretroviral therapies were disrupted because certain drugs ceased to be economically available; a number of PLWHA had to then switch to different medicines that come at cheaper prices.

New biomedical technologies in HIV/AIDS prevention are not usually promoted or embraced by state institutions with enthusiasm. Instead, as has been true in the past, communities and social movements are driving the implementation by the state of novel healthcare programs. In his contribution to the issue, Karsten Schubert uses the term "democratic biopolitics" to name "the agency of citizens and activists, and their active participation in biopolitics." "Democratic biopolitics" is thus social 
change enacted at the grassroots level, in community-based settings. Vibrant, positive PrEP and $U=U$ discourses in social and public spheres and policy implementations in these areas are manifestations of the "democratic biopolitics" Schubert advocates.

By bringing together the voices of academics and activists from different countries and regions, this issue offers a look at epidemics and pandemics through a dynamic, sometimes contradictory and unstable, lens. Narratives about the past, present and future enable us to see health, life, and death in their relational, affective, yet material forms, intersecting with inequalities and power dynamics. At the same time, they demonstrate the unprecedented importance of community and grassroots mobilization in the struggle for health and treatment rights, sexual expressions and pleasures.

\section{Works Cited}

Chantraine, Renaud, Florent Molle and Sandrine Musso (2019), "AIDS Politics of Representation and Narratives: A Current Project at the Museum of European and Mediterranean Civilizations (Mucem) in Marseilles, France", Oncurating.org, 42: 206-218.

Dean, Tim (2015), "Mediated intimacies: Raw sex, Truvada, and the biopolitics of chemoprophylaxis", Sexualities, 18.1/2: 224-246. https://doi.org/10.1177/1363460715569137

Dziuban, Agata, Friederike Faust, Todd Sekuler, Justyna Struzik, Linda Bonde and Emily Jay Nicholls (2021), "HIV/AIDS and its monsters. Negotiating criminalisation along the monster-human continuum", European Journal of Cultural Studies. https://doi.org/10.1177/13675494211017911

Grace, Daniel, Jody Jollimore, Paul MacPherson, Matthew J.P. Strang and Darrell H.S. Tan (2018), "The Pre-Exposure Prophylaxis-Stigma Paradox: Learning from Canada's First Wave of PrEP Users", AIDS PATIENT CARE and STDs, 32.1: 24-30. https://doi.org/10.1089/apc.2017.0153

Kelly, Ann H., Frédéric Keck and Christos Lynteris (eds.) (2019), The Anthropology of Epidemics, London, New York, Routledge.

Lee, Nathan (2013), "Becoming-undetectable", e-Flux Journal 44, https://www.eflux.com/journal/44/60170/becoming-undetectable/

Malinowska, Kasia (2017), "Polish Drug Policy", European Drug Policies: The Ways of Reform, Renaud Colson and Henri Bergeron (eds.), New York, Routledge: 149-163. https://doi.org/10.4324/9781315690384

Owczarzak, Jill (2010), "Activism, NGOs, and HIV Prevention in Postsocialist Poland: The Role of 'Anti-Politics'", Human organization, 69.2: 200-211, https://doi.org/10.17730/humo.69.2.v8132n668713242k

Price-Smith, Andrew T. (2009), Contagion and Chaos. Disease, Ecology, and National Security in the Era of Globalization, Cambridge, Massachusetts, the MIT Press.

Race, Kane (2018), The Gay Science. Intimate Experiments with the Problem of HIV, New York, Routledge.

Rosengarten, Marsha, Todd Sekuler, Beate Binder, Agata Dziuban and Peter-Paul Baenziger (2021), "Beyond Biological Citizenship: HIV/AIDS, Health, and Activism in Europe Reconsidered", Critical Public Health, 31.1: 1-4, https://doi.org/10.1080/09581596.2020.1851656

Struzik, Justyna (2021), "Citizenship and pleasure: a study on harm reduction assemblages in Poland", Critical Public Health, 31.1: 30-42, https://doi.org/10.1080/09581596.2020.1849562 